\title{
MANIFESTAÇÕES DE GÊNERO NA NARRATIVA BRASILEIRA CONTEMPORÂNEA E SUAS REPERCUSSÕES NO ENSINO DE LITERATURA: UMA ANÁLISE DA OBRA ENFIM, IMPERATRIZ, DE MARIA FERNANDA ELIAS MAGLIO
}

\begin{abstract}
Gender Manifestations in Brazilian Contemporary Literature and their Repercussions on Teaching Literature: an Analysis of the Book Enfim, Imperatriz, by Maria Fernanda Elias Maglio
\end{abstract}

\author{
Gabriella Chitolina Cardoso ${ }^{1}$ \\ Cimara Valim de Melo ${ }^{2}$
}

A literatura confirma e nega, propõe e denuncia, apoia e combate, fornecendo a possibilidade de vivermos dialeticamente com os problemas.

Antonio Candido

\begin{abstract}
Resumo: A literatura brasileira no cenário atual tem, cada vez mais, buscado representar indivíduos invisibilizados pela sociedade. Assim, destaca-se a contribuição de escritoras contemporâneas, muitas das quais têm abordado personagens subalternizadas e fomentado o debate sobre questões de gênero sob uma perspectiva decolonial. Entre elas está a escritora Maria Fernanda Elias Maglio, autora do livro de contos Enfim, Imperatriz, publicado em 2017 e vencedor do prêmio Jabuti no ano de 2018. Tomando como base a referida obra literária, o presente artigo objetiva analisar a maneira pela qual a autora retrata as relações de gênero e, mais especificamente, perceber como os contos "Viva em Maputo" e "Geni" representam a objetificação social, a violência e a própria (de)colonialidade. Em sua metodologia, a pesquisa, de abordagem qualitativa, contou com a análise bibliográfica para a investigação da narrativa brasileira do século XXI em termos teórico-críticos. Como resultados, percebe-se uma forte representatividade feminina na obra de Maglio, bem como a presença da objetificação social em diferentes contextos sociais retratados pelos contos, elementos que podem corroborar o trabalho docente e trazer repercussões positivas ao ensino de literatura, fomentando a leitura do mundo e o olhar atento acerca das relações de alteridade. A partir das análises, observa-se a necessidade da construção de uma educação minorizante, que aborde questões sociais da contemporaneidade pelo viés do indivíduo descentrado e culturalmente marginalizado, em um movimento de transgressão cultural frente às estruturas dominantes de poder.
\end{abstract}

\footnotetext{
${ }^{1}$ Estudante do Curso Técnico em Administração Integrado ao Ensino Médio do Instituto Federal de Educação, Ciência e Tecnologia do Rio Grande do Sul (IFRS). Bolsista de iniciação científica do projeto de pesquisa Transnacionalidades: literatura brasileira contemporânea e(m) tradução. Orcid: https://orcid.org/0000-00018231-0974. Contato: gabichitolina03@gmail.com

${ }^{2}$ Professora do Instituto Federal de Educação, Ciência e Tecnologia do Rio Grande do Sul (IFRS). Doutora em Letras (UFRGS), com pós-doutorado pelo King's Brazil Institute (KCL). Orcid: https://orcid.org/0000-00031145-3438. Contato: cimara.valim @gmail.com.
} 
Palavras-chave: Literatura brasileira contemporânea. Decolonialidade. Gênero. Educação minorizante.

\begin{abstract}
In the current scenario, Brazilian literature has increasingly sought to represent individuals who are made invisible by society. In this perspective, contemporary women writers have played an important role by contributing to the purpose of approaching subalternized characters and feeding the debate about gender issues through a decolonial view. Amongst them, there is Maria Fernanda Elias Maglio, author of the book of short stories Enfim, Imperatriz, published in 2017 and winner of the Jabuti award in 2018. Based on the aforementioned literary work, this article aims to analyze the way in which the author portrays gender relations and, more specifically, to understand how the short stories "Viva em Maputo" and "Geni" represent social objectification, violence and (de)coloniality itself. In methodological terms, the research, with a qualitative approach, relied on the bibliographic analysis for the investigation on the 21st century Brazilian narrative in theoretical and critical terms. As a result, there is a strong female representation in Maglio's work, as well as the presence of social objectification in different social contexts portrayed by the stories, elements that can corroborate the teaching work and bring positive repercussions to the teaching of literature, encouraging the reading of the world and the attentive look at the relationships of otherness. From the analysis, it is possible to observe the need to build a minorizing education, which addresses contemporary social issues through the bias of the decentralized and culturally marginalized individual, in a movement of cultural transgression in front of the dominant structures of power.
\end{abstract}

Keywords: Contemporary Brazilian Literature. Decoloniality. Gender. Minoritizing education.

\title{
1 Introdução
}

A contemporaneidade traz consigo novas visões e questionamentos referentes a questões sociais como gênero, raça, sexualidade, religião e classe. Essas problemáticas têm sido cada vez mais abordadas no cotidiano, havendo assim um forte eco social responsável por trazê-las para os universos literário e acadêmico. Elas carregam em si aspectos da decolonialidade, a qual, para o semiólogo argentino Walter Mignolo (2017, p. 13), é a resposta para as falácias e as falsas promessas de progresso contempladas pela modernidade. Dessa forma, a literatura brasileira contemporânea tem refletido acerca de formas de pensamento enraizadas às estruturas sociais, trazendo consigo pautas referentes a desigualdade social, violação de direitos humanos e desrespeito à diversidade cultural. Assim, a literatura abre espaços para que grupos marginalizados sejam ouvidos e age em prol do pensamento decolonial, visto por Renata Rafaela Borges da Silva (2020a, p. 15) como "comprometido com a igualdade e a justiça social, levando à reflexão acerca dos pensamentos e atitudes dos padrões já consagrados pelas sociedades dominantes".

Uma literatura decolonizante preocupa-se em abordar perspectivas do indivíduo descentrado, culturalmente apagado ou censurado pela literatura colonial canônica. Tal noção faz com que espaços e indivíduos periféricos e subalternizados estejam em pauta, trazendo uma maior representatividade social à narrativa. Neste contexto de decolonialidade representado pelo literário, tem se tornado recorrente a presença de escritoras interessadas em abordar questões antes esquecidas, ocultas ou apagadas na/pela literatura, ao mesmo tempo em que surgem leitores(as) cada vez mais ávidos(as) por leituras que retratam a sociedade de forma pungente e que tragam para o centro do debate a diversidade como algo real, presente 
na sociedade, a moldar experiências individuais e coletivas. Dessa forma, a produção contemporânea ganha destaque no cenário atual, visto que abre espaço ao desenvolvimento de uma literatura comprometida com a humanização e torna-se, como destaca Antonio Candido (2004, p. 175), um "instrumento poderoso de instrução e educação, entrando nos currículos, sendo proposta a cada um como equipamento intelectual e afetivo".

É com esse local de fala que surge a literatura de Maria Fernanda Elias Maglio escritora premiada e defensora pública no estado de São Paulo. ${ }^{3}$ Em seu livro de contos, Enfim, Imperatriz, lançado no ano de 2017 e ganhador do prêmio literário Jabuti no ano de 2018, a autora traz à tona histórias com uma forte variedade de espectros, os quais estão aliados a críticas sociais, representadas em enredos que envolvem relacionamentos amorosos, distopia, e, acima de tudo, diferentes papéis ocupados pela mulher na contemporaneidade.

A obra Enfim, Imperatriz apresenta uma série de contos que, de diferentes maneiras, abordam questões de gênero na contemporaneidade. Dessa forma, este estudo tem o intuito de analisar como a autora retrata as relações de gênero em suas narrativas. Para isso, primeiramente; busca observar a presença do feminino nos papéis de narradora e protagonista; a seguir, quer compreender como os contos "Viva em Maputo" e "Geni" retratam a objetificação social e materialidade do feminino como um problema social em um espectro global ao longo do enredo.

Para tal análise, a pesquisa contou com uma abordagem qualitativa, tendo por ponto de partida dados coletados em 2019 pelo projeto "Transnacionalidades: Literatura Brasileira Contemporânea e(m) Tradução (IFRS)" com relação a autores(as) premiados e (não) traduzidos para a língua inglesa no século XXI, bem como à posição ocupada por mulheres escritoras entre autores premiados e traduzidos. Com base em sua finalidade, este trabalho priorizou uma metodologia que envolvesse a pesquisa bibliográfica, pela qual se buscou investigar a narrativa brasileira do século XXI em termos teórico-críticos.

A partir do estudo literário proposto, busca-se perceber a importância do literário a um ensino transgressor, que subverta as relações de poder dentro das instituições acadêmicas e oportunize novos mecanismos de representatividade social - aqui chamado de educação minorizante. Tomando como ponto de partida o conceito de tradução minorizante de Lawrence Venuti (1996), tem-se como proposta uma reflexão sobre o ensino de literatura brasileira contemporânea, vista aqui como veículo de problematização, resistência e reexistência a partir de espaços proporcionados para que diferentes vozes sejam ouvidas e valorizadas.

\section{0 papel da narração como fonte de representatividade em Enfim, Imperatriz}

As narrativas que compõem a obra Enfim, Imperatriz, de Maria Fernanda Maglio, conferem papéis de protagonismo a personagens femininas. Dos dezessete contos apresentados pela autora, onze são protagonizados por mulheres, o que demonstra a sua posição de destaque na produção de Maglio, em seus diversos espectros socioculturais. Tais representações refletem relações do indivíduo com a sociedade, podendo ser variáveis e determinadas por relações de poder (ROSSINI, 2016, p.100). Essa variedade de representações faz com que se torne possível a visualização do corpo feminino em contextos distintos, removendo-o do seu papel socialmente imposto de mulher submissa e devota ao homem e aos filhos. Para Rossini (2016, p. 101), com a produção literária de autoria feminina,

\footnotetext{
${ }^{3}$ Livros publicados: Enfim, Imperatriz (2017), vencedor do Prêmio Jabuti na categoria contos; 179. Resistência (2019), vencedor do vencedor do Prêmio Alphonsus de Guimaraens de Poesia da Biblioteca Nacional; Você me espera para morrer? (2020)
} 
as personagens ganharam o direito à voz, tornando-se, não raro, narradoras e, como tal, passaram a representar experiências femininas que se distanciam da perspectiva hegemônica masculina.

Nesse sentido, a narrativa em primeira pessoa assume maior poder de expressão dentro da obra, conferindo destaque ao 'eu' nela representado. Cabe ao narrador definir por qual perspectiva a história será contada e como cada personagem será definida dentro da trama. Como traz Luana Teixeira Porto (2017, p. 216), a narração em primeira pessoa tem o papel de subjetivar a narrativa, conduzindo o(a) leitor(a) a registrar uma visão da personagem e, assim, espelhar vivências e representações coletivas. Com isso, percebe-se como o ato de trazer a representatividade para a narração pode ser uma forte ferramenta de autoidentificação dentro da narrativa. No caso de Maglio, a narração em primeira pessoa é constantemente utilizada como forma de representar a subjetividade atribuída às personagens. Dos dezessete contos, onze são narrados em primeira pessoa, e, destes, sete são narrados por mulheres. A presença de uma narradora na obra faz com que a personagem possa ser vista de forma mais verossímil, sem o 'olhar ilusório' do masculino.

\subsection{Viva em Maputo}

O conto "Viva em Maputo" retrata a história de Joseli Maria de Lima, um frentista que lê no jornal o estupro seguido de um feminicídio de uma gasolineira na cidade de Maputo, capital de Moçambique. Para Carlos Magno Gomes (2015, p.201), o feminicídio se refere a uma violência motivada por questões simbólicas e normas coletivas, as quais se encontram inseridas em um contexto de masculinidade hegemônica, definida como uma "configuração de gênero que incorpora a resposta atual aceita para o problema da legitimidade do patriarcado garantindo a posição dominante dos homens e a subordinação das mulheres" (CONNEL apud GARCIA, 1998, p.46). Após ler a notícia, a protagonista se vê estranhamente representada no corpo daquela mulher.

A morte do jornal era vermelha. E era eu. Não, eu não estava morta. Viva como toda gente viva, fazendo bico de frentista no posto do seu Leomar. Velho porco que mantinha na minha bunda os olhos, e às vezes as mãos. A foto estava morta, a foto era eu. (MAGLIO, 2017, p.75)

Essa representação trabalhada pela autora carrega o peso não só do ser feminino, mas também revela a autorrepresentação da mulher negra como alvo de violência e objetificação do seu corpo e de sua sexualidade, atreladas a concepções racistas reproduzidas (QUEIRÓZ; TEIXEIRA, 2017, p. 5) pelo patriarcado e pela branquitude. Isso se remete à concepção do corpo negro como objeto material de prazer (FROZ; SANTOS, 2015, p. 164), fruto de uma colonização escravista e hegemônica, que pregava a miscigenação como forma de embranquecer e, assim, "melhorar" a sociedade. A título de exemplo, percebe-se, a partir de dados coletados pelo Instituto de Pesquisa Econômica Aplicada (IPEA), que, enquanto houve um decréscimo nas taxas de homicídio de mulheres não negras entre os anos de 1997 e 2017, houve um crescimento nessa mesma taxa para as mulheres negras (IPEA, 2020). Tais dados comprovam a situação de subalternidade e vulnerabilidade da mulher negra na sociedade brasileira contemporânea, cuja condição é capturada pelas lentes narrativas de Maglio.

Com isso, a narradora, protagonista da trama, passa a se entender como uma mulher morta e a refletir acerca da causa e das motivações que a levaram à morte. Nesse ponto, a autora promove uma reflexão acerca da maternidade, mesmo considerando um cenário de estupro e violência, trazendo à tona a violência simbólica, pela qual, mesmo considerando o 
cenário de estupro e feminícidio sofridos pela gasolineira, a noção de maternidade, que constitui a imagem feminina historicamente, ainda se reflete. Nesse sentido, em sua análise sobre o contemporâneo, Tiburi $(2018$, p. 105) traz à tona as palavras gregas pólis, cidadeEstado, e óikos, território da casa - "o primeiro é reservado aos homens e o segundo, às mulheres, aos escravos e aos animais", o que demonstra o lugar minoritário por elas ocupado, geralmente vinculado ao papel de reprodutora. "No espaço da casa, há o trabalho, a procriação e a sustentação organizada da vida. Essa separação entre público e privado coloca homens e mulheres (e escravos e animais) em mundos separados" - segregação que a sociedade contemporânea ainda reproduz. Assim, pode-se perceber como Maglio aborda a maternidade compulsória que envolve o ser feminino e a constante presença dessa questão no cotidiano das mulheres.

Eu estava morta no instante em que ele gozou? O monstro? Primeiro me abriu a barriga com a lâmina da faca e depois empalou meu corpo morto? Ou gozou no meu útero vivo, prometendo descendentes da minha miséria? Torceu a faca na minha barriga no momento em que a genética dele se misturava com a minha (preta, pobre, frentista, mulher) abortando meu filho quase concebido? (MAGLIO, 2017, p.76)

A narrativa ainda aborda a globalização da violência contra a mulher ao representar a diferença espacial entre Rio de Janeiro e Maputo. Tal diferença demonstra que, até mesmo em continentes diferentes, a figura da mulher se mantém enquanto papel de objetificação e alvo de violência, considerando as duas vozes opressoras do conto, o assassino, desconhecido na narrativa, e Seu Leomar, chefe de Joseli. Ao se abordar a violência contra a mulher não como um ato isolado, mas a partir de um contexto coletivo global, percebe-se a amplitude dessa questão como um problema humanitário e transcontinental.

\author{
Eu violada \\ Ela violada \\ Eu Rio de Janeiro \\ Ela Maputo \\ (MAGLIO, 2017, p.74)
}

Ao longo dos primeiros parágrafos do conto, a protagonista lida com a descoberta de sua morte e reflete, pela incidência do duplo na narrativa, sobre como se sente ao empreender outro tempo-espaço, pensando com certa melancolia sobre sua vida e sua morte. "Acendi um cigarro em pesar da minha morte e em louvor à minha vida. Estava morta em Maputo. Onde quer que fosse isso." (MAGLIO, 2017, p.76). A personagem, agora duplicada, torna-se, paradoxalmente, uma amálgama de duas vidas, ao mesmo tempo tão próximas e diferentes.

No entanto, com o desenvolvimento da narrativa, esse sentimento abandona seu ar melancólico e se transforma em raiva intensa, em um impulso desesperado por justiça. Joseli deixa de se perceber como uma mulher assassinada em Maputo e começa a se entender como estando viva no Rio de Janeiro. Sua sobrevivência significava a sobrevivência do seu eu em Maputo, e é com essa concepção que ela decide voltar à vida e lutar contra seu agressor: "Eu estava viva. Se não era passado, eu temia que fosse futuro. Que o destino sacana pudesse estar me designando barriga aberta e sexo transgredido. Se o monstro ainda não tinha me matado e empalado, eu matava e empalava o monstro.” (MAGLIO, 2017, p. 77)

No dia seguinte, ela, viva, vai ao encontro de Seu Leomar com o intuito de finalmente se vingar por tudo que ele fez por ela e pelo seu eu em Maputo. Seu Leomar, nesse momento, deixa de ser um indivíduo, passando assim a representar a masculinidade como um todo. 
Joseli, ao confrontá-lo, confronta-se diretamente com o machismo e as violências do ser masculino. Com isso, ela traz a vida de volta para si e seu outro eu, utilizando-se, para isso, da canção de Chico Buarque (2006) ${ }^{4}$, a qual serve como intertexto fundamental: "Porque era ela / Porque era eu" (MAGLIO, 2017, p. 73).

\begin{abstract}
Ele morto. Eu viva. No Rio de Janeiro. No diabo de um lugar chamado Maputo. Eu viva pra sempre. De mancha na boca e amarelo nos dentes. Viva. Sem filho no útero, sem terra, nem flor de defunto. Se eu estava viva, ela não estava morta. Poderia se levantar no sono cinza do jornal e desencardir o sangue do vestido vermelho. Viva em Maputo. Eu era ela. Ela era eu. (MAGLIO, 2017, p. 78)
\end{abstract}

Por meio do conto analisado, é possível perceber a maneira pela qual a autora retrata a autoidentificação feminina a partir do viés da violência de gênero sofrida por grande parte das mulheres. No Brasil, em 2018, a cada duas horas uma mulher foi assassinada (IPEA, 2020, p. 37); observa-se, com os dados acima, como a violência de gênero está moldada em nossa sociedade e como as literaturas que abordam essas questões se fazem necessárias. Pelo conto de Maglio, é levantada a pauta da coletividade que move as lutas pela igualdade de gênero: uma mulher vê-se representada em outra, e isso a move. Deste modo, o conto termina com um confronto direto à ideologia da masculinidade hegemônica que rege nossa sociedade e nossas relações interpessoais, demonstrando a importância da identificação e da sororidade para as lutas sociais.

\title{
2.2 Geni
}

O conto "Geni" retrata a história de uma personagem homônima, uma prostituta cuja história foi inspirada na música "Geni e o Zepelim" de Chico Buarque 5 . Conforme a justificativa dada na abertura do conto (MAGLIO, 2017, p. 101), ela começou a trabalhar com dezesseis anos, não em busca de dinheiro, mas por pena das pessoas que vinham visitá-la e procurar seus serviços. Essa contextualização inicial coloca a protagonista, já de início, em um espaço de deslocamento e, consequentemente, reposiciona o lugar da mulher prostituída frente ao todo masculino: "Não fazia sexo por dinheiro. Por prazer, tampouco. Fazia por pena." (MAGLIO, 2017, p. 101).

Não tinha identidade ou certidão de nascimento. Geni apenas sabia que fazia aniversário no mês de dezembro, junto com Jesus Cristo, por isso, não trabalhava naquele mês. Vestia suas calças compridas e, por mais que lhe implorassem, em dezembro não havia pecado. Para Geni, o mês de dezembro era seu momento de maior felicidade, em meio à castidade e à ausência da violência imposta pelo sexo. "Pouco saía de casa em dezembro. Ia até o quintal estender a roupa e ao mercadinho comprar ovo, sabão, sal. Nunca foi tão feliz quanto nesses dezembros de solidão" (MAGLIO, 2017, p. 103). Em seu artigo Contingent foundations: Feminism and the question of 'postmodernism', a filósofa Judith Butler (1994, p. 27) aborda o sexo, em seu sentido político, como um mecanismo de violência silencioso,

\footnotetext{
${ }^{4}$ A canção "Porque era ela, porque era eu", de Chico Buarque, foi inspirada na popular frase do filósofo Michel de Montaigne - Parce qu'était lui, parce qu'était moi - (BUARQUE, 2014), a qual tem, na intenção de explicação, a recusa, ou seja, a negação do próprio ato de explicar, cujo paradoxo pode também ser concebido como resistência. Na canção, o gênero do pronome pessoal é alterado do masculino (lui) para o feminino (ela).

${ }^{5}$ A canção "Geni e o Zepelim", de Chico Buarque, foi composta para a peça brasileira "Ópera do Malandro" no final dos anos 1970 (DUNDER et al., 2015), período de forte opressão e de censura impostas pela Ditadura Militar brasileira.
} 
característica perceptível ao longo do conto pelo modo que este representa as violências cotidianas sofridas por Geni em sua profissão.

Contudo, em um dia de dezembro, um homem de negócios chegou à cidade buscando ser atendido por Geni. Como forma de pagamento, prometeu reformar a praça da cidade se ela o atendesse, o que ela recusou - como antes dito, não havia pecado em dezembro. O homem ampliou suas promessas, prometeu reformar o hospital e reformar uma ponte da cidade. Após sua recusa, a cidade inteira se uniu para implorar à Geni o serviço, o que ela rejeitou reiteradamente. "Geni, nossa santa salvadora, nos salve. Geni, não te custa. É só fechar os olhos que num instante acaba. Ele prometeu ainda mais, reforma o hospital, dá uma reforçada na ponte que está para ruir." (MAGLIO, 2017, p. 104, grifo da autora).

Geni fez-se firme em sua decisão. Não abandonaria seus princípios de forma alguma. Por isso, logo esses pedidos generosos se tornaram agressivas ofensas. "Coloque-se no seu lugar, Geni. Puta não tem vontade. Abra as pernas de uma vez, mulher. Seja a puta que você é todo dia por um dia só." (MAGLIO, 2017, p.105). Geni resistia às ofensas e, com o passar do tempo, as frases caluniosas se tornaram apenas palavras soltas. Depois vieram as pedras, uma grande chuva de pedras disparadas em sua casa. Com o som das pedras batendo na sua porta, Geni rezava enquanto olhava o quadro de Jesus na sua parede, até que derrubaram sua porta e invadiram sua casa. Arrancaram suas roupas e a violentaram:

\footnotetext{
Depois veio o homem. Não se deu ao trabalho de despir. Arriou as calças até o joelho e trabalhou ofegante por alguns poucos minutos. Foi o primeiro a sair. Atrás dele a procissão de moradores. Ao todo vinte e oito homens fortes, dezessete fracos, trinta e uma mulheres e vinte e duas crianças, incluindo um bebê mamando na mãe. Também um banqueiro, um prefeito, um padre e um delegado. (MAGLIO, 2017, p. 106)
}

Quando ficou sozinha, olhou para o quadro de Jesus. Não sabia quando era seu aniversário, mas o dele aconteceria em poucas horas, era quase Natal - Geni havia sido violentada em todos os sentidos, em sua independência e vontade, em seu espaço e identidade. Conforme a síntese apresentada, é clara no conto a forma como a autora produz resistência ao retratar a violência contra a mulher. Geni, com sua vida inteira vista socialmente como insignificante, torna-se a salvação dos moradores da cidade, mas, para isso, passa a ser objeto de troca.

Quando ela demonstra e impõe suas vontades e seus princípios, é tratada como um corpo material sem interesses próprios, que pode ser usado da forma como os outros desejarem devido a sua condição subalterna. Assim, a narrativa vai ao encontro da canção de Buarque - "O seu corpo é dos errantes / Dos cegos, dos retirantes / É de quem não tem mais nada" (BUARQUE, 2013) no sentido de denúncia à violência de gênero; contudo, diferentemente da letra que inspira a história - "Foram tantos os pedidos / Tão sinceros, tão sentidos / Que ela dominou seu asco / Nessa noite lancinante / Entregou-se a tal amante / Como quem dá-se ao carrasco" (BUARQUE, 2013) - a protagonista de Maglio dá um passo a mais em direção à resistência, o que torna a violência ainda mais voraz: "Ela resistiu. Prendeu os polegares no passa-cinto das calças e rezou o pai-nosso. [...] Com um puxão, tiraram as calças que guardavam as pernas em dezembro." (MAGLIO, 2017, p. 106). Geni resiste, mas a violência contra a mulher se perpetua. 


\section{A objetificação do corpo feminino em "Viva em Maputo" e "Geni"}

Ambos os contos, "Viva em Maputo" e "Geni", retratam, de diferentes formas, a objetificação do feminino. No primeiro, percebe-se o papel do corpo da gasolineira como objeto de prazer momentâneo de seu assassino. A violência causada a ela se torna insignificante ao ser comparada às necessidades do seu agressor. No conto "Geni", a personalidade da protagonista já era vista como insignificante na perspectiva da sua cidade, vista a função social ocupada. Com a chegada do homem rico, há uma transformação em termos de importância dada à prostituta, pois, de um ser secundário, torna-se centro de interesse político na cidade, ou seja, objeto de troca. Assim, a sua individualidade, tal qual sua vontade, já não tem mais valor. Em seu papel de objeto de satisfação do outro, quando ela se recusa a reprimir seus princípios, a protagonista é violada da forma mais violenta e repudiável possível.

Nos contos analisados, é possível perceber como a autora retrata em sua obra territórios de subalternidade, demonstrando o papel representado pelo feminino dentro da narrativa. Tais representações de materialidade do ser feminino fazem parte da Teoria da Objetificação (FREDRICKSON; ROBERTS, 1997, p. 175), que elucida o papel da objetificação de mulheres na sociedade e como ela pode representar riscos à saúde mental das que são sexualizadas. Para os autores, a objetificação elucida o papel das mulheres como corpos usados para satisfazer o prazer de outros: "when objectified, women are treated as bodies - and in particular, as bodies that exist for the use and pleasure of others".

A objetificação sexual, expressa em ambos os contos, se refere ao momento em que o corpo de uma mulher é separado da sua individualidade e é visto apenas como um objeto inanimado cujo único papel é suprir os desejos sexuais masculinos (BARTKY apud SZYMANSKI; MOFFIT; CARR, 2011, p.8). Na trajetória das protagonistas, essa questão é levantada através de personagens na história: no conto "Viva em Maputo", por exemplo, a objetificação do feminino e o assédio sexual são observados a partir de duas personagens. A primeira, desconhecida, é o assassino da gasolineira em Maputo. Essa figura é responsável por demonstrar os extremos da violência contra a mulher. Já a segunda, Seu Leomar, representa uma figura assídua no cotidiano da maioria das mulheres: um homem hierarquicamente superior na relação funcionários/chefe, que se utiliza desse poder para assediar suas funcionárias sem que elas se pronunciem a respeito. Tal relação hierárquica dentro do ambiente de trabalho faz com que diversas mulheres não denunciem os abusos sofridos, pelo medo do desemprego ou por acreditarem que ninguém confiaria em suas palavras - abusos denunciados pela literatura de Maglio.

Já o conto "Geni" problematiza a objetificação de modo explícito, produzindo uma narrativa que traz em si a resistência de gênero. A protagonista, ao tomar uma decisão, vê-se deslegitimada pelos moradores de sua cidade frente à defesa de seu livre-arbítrio. Seus motivos foram ignorados, e seu corpo deixou de pertencer-lhe. O corpo de Geni passou a ser visto como um objeto de domínio pela cidade, com o qual os cidadãos podiam fazer o que desejassem. Ela passou a ser tratada como apenas um objeto validado pelo uso que os outros fizessem dele, objeto este que, segundo Fredrickson e Roberts (1997, p. 174), é indissociável de seu contexto sociocultural e se torna veículo de opressão de gênero quando sofre a objetificação sexual, denunciada pelo conto. Ele descortina o machismo, não como algo pontual de um indivíduo específico, mas como parte de um mecanismo de dominação do Estado, que corrobora o abalo das subjetividades do ser feminino. Para Assunção de Maria Sousa e Silva, "Os atos de violência do sujeito masculino sobre o feminino repercutem das estratégias e mecanismos de dominação do Estado, abalando, em maior medida, as 
subjetividades do ser feminino" (SILVA, 2020b, p.133). Dessa forma, é possível perceber o efeito das estruturas sociais como difusoras de ideais machistas que perpetuam estereótipos e violências dentro de nossa sociedade.

\section{Literatura minorizante como perspectiva de ensino}

Heloísa Buarque de Hollanda (2018, p.12) percebe a existência de uma nova geração política, na qual se inclui a luta feminista, com organização específica e em busca de equidades sociais. Uma geração "com estratégias próprias, criando formas de organização [...] autônomas, desprezando a mediação representativa, horizontal, sem lideranças e protagonismos", "valorizando mais a ética do que a ideologia, mais a insurgência do que a revolução". Tal constatação revela a ascendência de demandas na luta feminina, bem como uma maior necessidade de abordar questões de gênero em espaços de aprendizado, como o da sala de aula, seja em contexto físico ou virtual. Nesse sentido, trazer para o debate narrativas problematizadoras dessas questões torna-se fundamental, haja vista o papel transformador da literatura, que "humaniza em sentido profundo, porque faz viver." (CANDIDO, 2004, p. 176)

Com base nas relações produzidas entre a interculturalidade crítica e a construção de uma pedagogia decolonial (WALSH, 2009), observa-se, na literatura brasileira contemporânea, um território profícuo para a transformação do sujeito e a reflexão crítica. Por meio de um olhar transgressor, que visualize a produção não canônica como espaço de identificação e resistência, é mister oportunizar ao estudante de literatura uma leitura mais ampla do mundo e, consequentemente, um maior interesse pelo conteúdo a ser desenvolvido, proporcionando uma aprendizagem significativa que parta dos textos literários.

Nesse sentido, a 'literatura minorizante' - na esteira dos estudos de Venuti (1996) acerca de tradução minorizante ${ }^{6}$ - pode ser considerada forte aliada à formação leitora e cidadã. Chega-se, assim, à concepção de educação minorizante, pela qual questões subalternizadas podem ser representadas dentro do ambiente escolar, de forma que seja possível a criação de um espaço favorável à reflexão e à autocrítica, em uma proposta transversal de ensino que tome como base o letramento literário. Em seu livro Os sete saberes necessários à educação do futuro, o sociólogo e filósofo Edgar Morin (2000, p. 97) aborda as pré-concepções e a incapacidade de autocrítica como causas a tantas formas de incompreensão e intolerância. Percebe-se, portanto, a necessidade de uma educação que lide com questões socioculturais de forma aberta e enfática, produzindo mecanismos para o desenvolvimento de uma sociedade mais empática e engajada.

Nesse contexto, a autoidentificação torna-se um fator relevante dentro de uma proposta de educação minorizante, gerando leitores(as) mais interessados(as) e presentes dentro do processo literário e, consequentemente, mais suscetíveis a uma maior compreensão do mundo em termos estéticos e ideológicos. Por esta perspectiva, Luís Augusto Fischer (2011, p. 47) aponta que os livros "precisam do leitor que, em seu interior, sem ninguém outro para impor ritmo ou restrição, vai conectar informações, sensações, memórias, afetos, tudo isso e muito mais, e assim exercer sua prerrogativa humana de pensar construindo sentido". À vista disso, é perceptível a necessidade do trabalho com textos literários que problematizem

\footnotetext{
${ }^{6}$ Lawrence Venuti tem, em seu projeto de tradução minorizante, uma visão subversiva e ética da linguagem, pela qual são questionados processos de hegemonia cultural e relações desiguais de poder, dando voz a novos padrões e conferindo espaço a produções para além do cânone, nas quais são valorizadas a assimetria e a heterogeneidade (VENUTI, 1996, p. 92-93). Paralelamente, o ensino de literatura a partir de uma perspectiva de tradução minorizante confere protagonismo a autores e obras não canônicos do sistema literário, com vistas à problematização da dicotomia centro x periferia e à valorização de diferentes lugares de fala, nos quais estão incluídas as relações de gênero e a visão des-hegemonizante dos estudos literários.
} 
questões de gênero, trazendo uma representação mais verossímil da realidade - a exemplo da obra de Maglio. Aciona-se, desse modo, o literário em seu caráter humanizador, em busca de uma educação insurgente, emancipatória, cujos princípios estejam calcados no pensamento decolonial.

Para Paulo Freire (1989, p.9), o ato de ler ultrapassa a esfera da linguagem e envolve a leitura do mundo, com suas mazelas e subjetividades: "A leitura do mundo precede a leitura da palavra, daí que a posterior leitura desta não possa prescindir da continuidade da leitura daquele. Linguagem e realidade se prendem dinamicamente." Com isso, o papel da leitura crítica e das relações entre o texto literário e o contexto histórico-social que o envolve tornase essencial ao planejamento docente, tendo em vista sua posição de mediador(a) da aprendizagem pelos textos que seleciona, pelas atividades e estratégias propostas e pelas reflexões fomentadas em espaços físicos e virtuais de ensino-aprendizagem. Nesse sentido, Freire destaca a relevância da práxis pedagógica à transformação social: a leitura da palavra não é apenas precedida pela leitura do mundo, mas por uma certa forma de "escrevê-lo" ou de "reescrevê-lo", quer dizer, de transformá-lo através da prática consciente.

A professores(as) de literatura, cabe também a mudança de paradigmas em relação à dicotomia qualidade $\mathrm{x}$ quantidade quando o assunto é leitura. Freire já havia alertado para o efeito negativo da visão mágica da palavra escrita e a necessidade de leituras significativas a estudantes para além do número de páginas lidas.

\begin{abstract}
Creio que muito de nossa insistência, enquanto professoras e professores, em que os estudantes "leiam", num semestre, um sem-número de capítulos de livros, reside na compreensão errônea que às vezes temos do ato de ler. [...] A insistência na quantidade de leituras sem o devido adentramento nos textos a serem compreendidos, e não mecanicamente memorizados, revela uma visão mágica da palavra escrita. Visão que urge ser superada. A mesma, ainda que encarnada desde outro ângulo, que se encontra, por exemplo, em quem escreve, quando identifica a possível qualidade de seu trabalho, ou não, com a quantidade de páginas escritas. (FREIRE, 1989)
\end{abstract}

É, portanto, tarefa docente a promoção de espaços qualitativos de leitura e reflexão em prol do letramento literário e da formação cidadã - propósito que conduz à educação minorizante, à qual se associa a perspectiva decolonial. Quando um(a) estudante é instigado(a) ao confronto decolonizador por meio de textos literários que evoquem uma diversidade de lugares de fala (RIBEIRO, 2020), ampliam-se sua criticidade, sensibilidade e autonomia em relação ao mundo. É justamente essa sensibilidade que, de acordo com Freire (2000, p.60), precisa ser perseguida na luta por um mundo mais justo e livre: "Seria horrível se apenas sentíssemos a opressão, mas não pudéssemos imaginar um mundo diferente, sonhar com ele como projeto e nos entregar à luta por sua construção. [...] A liberdade não se recebe de presente, é bem que se enriquece na luta por ele $[\ldots . .$. ".

Ao encontro das questões levantadas por Freire $(1989,2000)$, a literatura brasileira tem se constituído como território permanente de lutas e de resistência ao longo das últimas décadas, de modo especial quanto a questões étnico-raciais e de gênero. Cada vez mais, observam-se escritores e escritoras engajados com os direitos humanos e a democratização da cultura, abrindo, por sua vez, espaços de fala a minorias diversas, que incluem a mulher e a subversão dos papéis sociais a ela conferidos pela tradição patriarcal. Isso contribui ao que Mignolo (2008, p. 137) chama de 'mudança nos termos da conversa': "Decolonial being, thinking, and doing begin from disrupting these assumptions and the naturalization of death. 
[...] decoloniality focuses on changing the terms of the conversation." (MIGNOLO, 2008, p. $127-130)^{7}$

Soma-se a tal cenário a promulgação da Lei $n^{\circ} 11.340$, de 7 de agosto 2006 - mais conhecida como Lei Maria da Penha - fundamental ao trazer à sociedade brasileira contemporânea bases legais para a promoção de "valores éticos de irrestrito respeito à dignidade da pessoa humana com a perspectiva de gênero e de raça ou etnia" (BRASIL, 2006). De fato, uma educação verdadeiramente humanizadora precisa estar atenta ao seu contexto histórico; hoje, acompanham-se movimentos antidemocráticos diversos, dentre os quais se situam a chamada "cruzada antigênero" (MELO, 2020), responsável por ações contra a "ideologia de gênero". Delas resulta a retirada do termo 'gênero' de documentos basilares à educação brasileira, como o Plano Nacional de Educação (PNE) e a Base Nacional Comum Curricular (BNCC) $)^{8}$. Contudo, a Lei Maria da Penha garante "o destaque, nos currículos escolares de todos os níveis de ensino, para os conteúdos relativos aos direitos humanos, à equidade de gênero e de raça ou etnia e ao problema da violência doméstica e familiar contra a mulher" (BRASIL, 2006). Essas premissas garantem à educação "uma força de mudança e de libertação", com a valorização do sujeito, o qual vai de encontro à "educação para a domesticação" e ao "homem-objeto" de que fala Freire (1967, p. 36), em uma postura de autorreflexão "e de reflexão sobre seu tempo e espaço".

Nesse contexto, a obra de Maglio oferece inúmeras possibilidades de reflexão em prol do exercício de autoconsciência, da humanização individual e coletiva e da libertação propostos por Walsh (2009), podendo ser utilizada como recurso pedagógico, com vistas aos letramentos literário e crítico, sob uma perspectiva de educação minorizante. Primeiramente, destaca-se o potencial da obra Enfim, Imperatriz como um todo, visto que as dezessete narrativas que a compõem oferecem espaços para que as vozes de mulheres anônimas, silenciadas e socialmente segregadas sejam escutadas, as quais, como observa Noemi Jaffe (2017, p.9-10), "gritam por serem ouvidas" e nos aproximam "do absurdo e da dor".

\begin{abstract}
Não há mais palavras para escrever um mundo vazio: das loucas, das bandidas, das putas, das prisioneiras, das mães solitárias, das filhas perdidas, das mulheres que ainda querem ser ouvidas. E não há mais como dizê-lo porque sua medida de realidade extrapolou o indizível e as palavras sempre soam ou muito poucas, ou muito banais ou inúteis. (JAFFE, 2017, p.9)
\end{abstract}

Mais especificamente em relação a "Viva em Maputo" e "Geni", percebemos que ambos os contos são rico material para análise e reflexão acerca da intertextualidade, de questões socioculturais representadas pelo literário e de perspectivas de gênero presentes nos diferentes pontos de vista da narrativa e na composição das personagens. Por exemplo, a autora inicia ambos os contos com intertextos de Chico Buarque, os quais não apenas abrem caminhos entre literatura e canção, mas também marcam a resistência poética face a condições de opressão e dominação experienciadas pelas personagens femininas.

Em "Viva em Maputo", a relação eu x outro pelo viés do duplo - Eu preta, Ela preta / Eu favela, Ela caniço / Eu pobre, Ela pobre” (MAGLIO, 2017, p. 73) - é um elemento bastante presente e interessante de ser explorado, pois tece, na estrutura narrativa, as conexões entre identidade e alteridade provenientes do discurso da narradora. Outro elemento que exerce força no conto diz respeito à organicidade espaço-temporal e sua repercussão

\footnotetext{
7 Tradução nossa: “O ser, o pensar e o fazer decolonial começam pela desestabilização de pressupostos e pela naturalização da morte [...] a decolonialidade centra-se na mudança dos termos da conversa."

8 Para mais informações, podem ser acessados os sites do Governo Federal http://pne.mec.gov.br/ e http://basenacionalcomum.mec.gov.br/.
} 
subjetiva, tendo em vista que condições semelhantes de violação de direitos são percebidas mesmo em continentes distintos - América e África, Brasil e Moçambique, Rio de Janeiro e Maputo. Uma foto e uma notícia desencadeiam um momento epifânico na narradora - "preta e pobre" (MAGLIO, 2017, p. 75) - e, por conseguinte, influenciam em suas ações rumo ao desfecho da narrativa. O conto, de apenas seis páginas, coloca em prática o ingrediente da intensidade, presente nas teorias do conto de Edgar Allan Poe (1985) e Julio Cortázar (2006), cujos textos também merecem ser explorados, no todo ou em parte, em sala de aula, para uma melhor compreensão do gênero. A tensão que acompanha a narrativa pode ser abordada didaticamente, a fim de que sejam discutidas, a partir dela, questões relativas à violência enraizada a um mundo ainda preso ao patriarcalismo colonial. Maglio abre caminho, assim, a mulheres em situação de vulnerabilidade, socialmente ignoradas, mas muito presentes nas estatísticas registradas no Atlas da Violência (IPEA, 2020), em especial quando se fala de violência contra mulheres negras.

De extensão e intensidade semelhantes, o conto "Geni”" aborda a violência de gênero pelo viés da prostituição. Geni, aqui conhecida a partir de uma narrativa em terceira pessoa, atua como objeto de satisfação de uma cidade inteira; contudo, é pelo seu corpo que ela mesma resistirá a uma existência de violação e ao apagamento enquanto sujeito frente a uma sociedade sexista e cruel. A descrição da personagem é um elemento importante a ser analisado, visto que escancara a sua condição subalterna: "não tinha carteira de identidade e nem certidão de nascimento, de modo que nem mesmo ela sabia ao certo quantos anos tinha e nem o dia exato de seu aniversário" (MAGLIO, 2017, p. 102). Novamente, a obra de Chico Buarque está presente como intertexto na abertura do conto, e as relações entre Música Popular Brasileira (MPB) e literatura tornam-se caminhos possíveis em termos pedagógicos, em especial pelo modo como fazem resistência às injustiças sociais. Geni resiste pelo silêncio - "Diante do silêncio resistente da moradora de calças compridas os pedidos deram lugar às ofensas [...]. Ela resistiu." (MAGLIO, 2017, p. 105-106). O conto, todavia, à semelhança da canção "Geni e o Zepelim", é um grito de recusa e transgressão, uma "forma de resistência simbólica aos discursos dominantes", pelo qual se percebe ora a recuperação do sentido comunitário perdido, ora a melodia dos afetos em plena defensiva, ora a crítica da desordem estabelecida, como sugere Alfredo Bosi (1977, p. 144).

Tais mecanismos de resistência, seja no conto de Maglio, seja na canção de Buarque ou na crítica de Bosi, podem ser amplamente explorados em espaços de ensino-aprendizagem de língua e literatura, levando-se em conta a formação leitora e o desenvolvimento do letramento literário. Enquanto 'outro' que testemunha a violação de Geni, o(a) leitor(a) é colocado(a) à prova: é a ele(a) que Geni pede humanidade. Assim, a narrativa pode ser lida como instrumento de denúncia da exploração sexual sob a ótica de minorias caladas por uma sociedade cujos valores variam conforme a posição social ocupada pelo indivíduo. As conexões entre a Geni de Chico Buarque e a de Maria Fernanda Maglio são possibilidades para o trabalho em sala de aula, tanto em meio físico quanto remoto. Quando discentes a leem e refletem sobre a exploração pelo olhar de minorias exploradas, abrem-se janelas para a leitura do mundo e o questionamento de mazelas que têm assolado o tempo presente.

Se, por um lado, é necessário levar em consideração a faixa etária discente para o trabalho com textos literários que representam violências diversas, por outro urge fomentar os direitos e objetivos de aprendizagem vinculados ao desenvolvimento de estudantes, tal como expresso nas competências da BNCC do Ensino Médio (BRASIL, 2018, p.4, grifo nosso):

VII - Argumentar com base em fatos, dados e informações confiáveis, para formular, negociar e defender ideias, pontos de vista e decisões comuns, que respeitem e promovam os direitos humanos, a consciência socioambiental e o consumo 
responsável em âmbito local, regional e global, com posicionamento ético em relação ao cuidado de si mesmo, dos outros e do planeta.

VIII - Conhecer-se, apreciar-se e cuidar de sua saúde física e emocional, compreendendo-se na diversidade humana e reconhecendo suas emoções e as dos outros, com autocrítica e capacidade para lidar com elas.

IX - Exercitar a empatia, o diálogo, a resolução de conflitos e a cooperação, fazendo-se respeitar e promovendo o respeito ao outro e aos direitos humanos, com acolhimento e valorização da diversidade de indivíduos e de grupos sociais, seus saberes, identidades, culturas e potencialidades, sem preconceitos de qualquer natureza.

Acredita-se, portanto, que a obra Enfim, Imperatriz possui potencial para trazer repercussões positivas no ensino de literatura, fomentando a leitura do mundo e o olhar atento acerca das relações de alteridade. Isso porque as narrativas ali presentes trazem consigo elementos para que estudantes possam vislumbrar a vida alheia por uma perspectiva decolonial ao mesmo tempo em que, como diz Jaffe (2017, p.11), consiga ampliar "nosso sentido de humanidade e de tolerância". O trabalho docente, quando aberto a autores(as) e obras representativos(as) da diversidade cultural e de identidades em (re)afirmação, repercute na formação cidadã das novas gerações, constituindo o que Mignolo e Walsh (2018, p. 3) intitulam "reexistência" para além da resistência, compreendida como a redefinição e a ressignificação da vida em condições de dignidade. Por conseguinte, somente com uma transformação que passa pela visão de mundo e de indivíduo será possível apreender, na esfera educacional, a dimensão de cultura perseguida por Paulo Freire (1967, p. 108-109):

\begin{abstract}
A dimensão humanista da cultura. A cultura como aquisição sistemática da experiência humana. Como uma incorporação, por isso crítica e criadora, e não como uma justaposição de informes ou prescrições "doadas". A democratização da cultura - dimensão da democratização fundamental.

[...] tanto é cultura o boneco de barro feito pelos artistas, seus irmãos do povo, como cultura também é a obra de um grande escultor, de um grande pintor, de um grande místico, ou de um pensador. Que cultura é a poesia dos poetas letrados de seu País, como também a poesia de seu cancioneiro popular. Que cultura é toda criação humana.
\end{abstract}

\title{
5 Considerações finais
}

Por meio deste trabalho, pode-se observar como a masculinidade hegemônica moldou, e continua moldando, a sociedade em termos socioculturais. No entanto, percebem-se diferentes movimentos em prol de uma mudança de perspectiva na contemporaneidade, os quais contribuem à decolonialidade e trazem à luz a figura do indivíduo descentrado, em espaços periféricos e marginalizados pelas estruturas hierárquicas sociais. Nesse sentido, o sistema literário contemporâneo, composto cada vez mais por escritoras e escritores a representar indivíduos subalternizados e constantemente apagados ou esquecidos pela matriz colonial de pensamento, embebe-se da perspectiva decolonial, trazendo uma maior representatividade para suas obras.

Nesse contexto, a escritora Maria Fernanda Elias Maglio corrobora as escritoras contemporâneas que retratam questões de gênero dentro de suas produções, fazendo do universo literário espaço de resistência e denúncia social. A obra Enfim, Imperatriz junta-se a essas vozes, abrindo um leque de possibilidades com vistas à representação do feminino. Ao retratar papéis sociais comumente conferidos à mulher, bem como violências por ela sofridas e espaços ao mesmo tempo conquistados e tolhidos, a autora produz um lugar de fala próprio (RIBEIRO, 2020, p. 89), pelo qual rompe "com um silêncio constituído para quem foi 
subalternizado" e com uma hierarquia violenta, calcada na lógica perpetuadora da injustiça social. Esses novos olhares trazem à tona as manifestações de gênero, suas possibilidades de representação das diferenças, de identidades individuais e coletivas, ampliando as perspectivas acerca do ser feminino, em contraste com as concepções e os preconceitos trazidos pela masculinidade hegemônica à sociedade brasileira contemporânea.

As análises dos contos "Viva em Maputo" e "Geni” buscaram identificar como Maglio reflete, por meio da representação de papéis conferidos à mulher, a realidade social e as lutas cotidianas enfrentadas na busca pela igualdade de gênero. A partir do estudo realizado, foi possível observar modos de abordagem da materialidade e da objetificação do corpo feminino na literatura brasileira do século XXI. Por exemplo, percebe-se, no conto "Viva em Maputo", como a violência contra a mulher está ainda engendrada a práticas sociais cotidianas e se insere em nível global. Ao abordar a história de duas mulheres em países diferentes e retratar similaridades entre elas, como a cor da pele e a classe social, a autora constrói um ambiente de forte representação do corpo e expressa a globalidade do machismo e da violência. Já o conto "Geni", ao ter como protagonista uma prostituta desrespeitada em sua liberdade sexual, representa a violência contra a mulher a partir da combinação entre marginalização e exploração sexual, incorporando discursos machistas ao longo do texto para, então, resistir à visão da mulher como um ser objetificado. Tal resistência intensifica-se pelo retrato da animalização do ser, que limita a liberdade e afronta a dignidade humana no momento em que a vontade do outro reproduz as estruturas patriarcais do Estado.

Por fim, nota-se a importância de que narrativas como as encontradas em Enfim, Imperatriz estejam presentes não apenas no sistema literário atual, mas também no ambiente educacional, como um mecanismo de (auto)identificação e representação das diferenças, formando indivíduos mais empáticos, críticos e envolvidos socialmente. Para Candido (2004, p. 186), a literatura, em sua luta pelos direitos humanos, "pode ser um instrumento consciente de desmascaramento, pelo fato de focalizar as situações de restrição dos direitos, ou de negação deles". É justamente aí que entra a perspectiva da educação minorizante, pela qual se faz possível promover, sob um olhar decolonial, a humanização, caracterizada por traços considerados essenciais, como "o exercício da reflexão, a aquisição do saber, a boa disposição para o próximo, o afinamento das emoções, a capacidade de penetrar nos problemas da vida, o senso da beleza, a percepção da complexidade do mundo e dos seres" (CANDIDO, 2004, p. 180).

Ao proporcionar que diferentes vozes sejam ouvidas e valorizadas, a literatura brasileira contemporânea favorece a ressignificação da vida em condições de dignidade, ou seja a reexistência de que fala Mignolo e Walsh (2018) - e, por isso mesmo, ações de promoção dos letramentos literário e crítico nunca foram tão necessárias. A problematização e a reflexão acerca das manifestações de gênero na literatura, como parte dessa diversidade a ser explorada em sala de aula, contribuem não apenas à formação de leitores(as) críticos(as), mas também ao desenvolvimento de indivíduos mais conscientes e atuantes no meio em que vivem, como prevê a BNCC (BRASIL, 2018), com posicionamento ético, respeito aos direitos humanos, valorização da diversidade de saberes, identidades e culturas, sem preconceitos ou intolerâncias.

\section{Agradecimentos}

O presente trabalho foi realizado com apoio do Instituto Federal de Educação, Ciência e Tecnologia do Rio Grande do Sul (IFRS), pelo qual as autoras agradecem. 


\section{Referências}

BOSI, Alfredo. O ser e o tempo da poesia. São Paulo: Cultrix, USP, 1977.

BRASIL. Lei n 11.340, de 7 de agosto de 2006. Diário Oficial da União, Brasília, 08 ago. 2006, p. 1. Disponível em:

https://legislacao.presidencia.gov.br/atos/?tipo $=$ LEI $\&$ numero $=11340 \&$ ano $=2006 \&$ ato $=4 \mathrm{~b} 0 \mathrm{gX}$ TU5kMRpWT5c7. Acesso em: 10 maio 2021.

BRASIL. Resolução CNE/CP 4/2018. Diário Oficial da União, Brasília, 18 dez. 2018, p. 120 a 122. Disponível em: http://portal.mec.gov.br/docman/dezembro-2018-pdf/104101-rcp00418/file. Acesso em: 05 mar. 2021.

BUTLER, J. Contingent foundations: Feminism and the question of 'postmodernism'. In: SEIDMAN, S. (ed.). The Postmodern Turn: New Perspectives on Social Theory. Cambridge: Cambridge University, 1994. p. 153-170.

BUARQUE, Chico. Geni e o Zepelim. [S. 1.: s. n.], 2013. 1 vídeo (5.36 min). Publicado pelo canal Biscoito Fino. Disponível em: https://www.youtube.com/watch?v=jWHH4MlyXQQ. Acesso em: 19 mar. 2021.

BUARQUE, Chico. O tempo e o artista: A canção, o rap, Tom e Cuba, segundo Chico. [Entrevista cedida a]o enviado especial a Roma e a Paris. Folha de São Paulo, São Paulo, 26 dez. 2004. Disponível em: https://www1.folha.uol.com.br/fsp/ilustrad/fq2612200408.htm. Acesso em: 14 maio. 2021.

BUARQUE, Chico. Porque era ela, porque era eu. Rio de Janeiro: Marola Edições Musicais, 2006. Disponível em: http://www.chicobuarque.com.br/letras/porqueeraela_06.htm. Acesso em: 14 maio. 2021.

CANDIDO, Antonio. O direito à literatura. In: CANDIDO, Antonio. Vários escritos. 4. ed. São Paulo; Rio de Janeiro: Duas Cidades; Ouro sobre Azul, 2004. p. 169-192.

CORTÁZAR, Julio. Alguns aspectos do conto. In: Valise de cronópio. São Paulo: Perspectiva, 2006.

DUNDER, Juliana Silva et al. De vilã a heroína: contextualizanado o estudo de gênero com a música “Geni e o Zepelim”. Anais XI CONAGES... Campina Grande: Realize, 2015. Disponível em: <http://editorarealize.com.br/artigo/visualizar/10572>. Acesso em: 14 mar. 2021.

FREDRICKSON, Barbara L.; ROBERTS, Tomi-Ann. Objectification theory: Toward understanding women's lived experiences and mental health risks. Psychology of Women Quarterly, n. 21, p. 173-206, 1997. Disponível em:

https://www.researchgate.net/publication/258181826_Objectification_Theory_Toward_Under standing_Women\%27s_Lived_Experiences_and_Mental_Health_Risks. Acesso em: 06 mar. 2021.

FISCHER, Luís Augusto. Filosofia mínima: ler, escrever, ensinar, aprender. Porto Alegre: Arquipélago, 2011. 
Revista de Educação, Ciência e Tecnologia
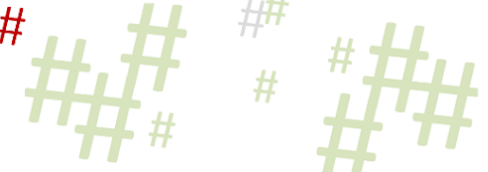

FREIRE, Paulo. Educação como prática da liberdade. Rio de Janeiro: Paz e Terra, 1967.

Disponível em: https://cpers.com.br/wp-content/uploads/2019/09/5.-

Educa\%C3\%A7\%C3\%A3o-como-Pr\%C3\%A1tica-da-Liberdade.pdf. Acesso em: 07 maio 2021.

FREIRE, Paulo. A importância do ato de ler. 23. ed. In: FREIRE, Paulo. A importância do ato de ler em três artigos que se completam. São Paulo: Cortez, 1989. Coleção Polêmicas do Nosso Tempo. Disponível em: https://cpers.com.br/wp-content/uploads/2019/09/1.-AImport\%C3\%A2ncia-do-Ato-de-Ler.pdf. Acesso em: 07 maio 2021.

FREIRE, Paulo. Pedagogia da indignação. São Paulo: UNESP, 2000. Disponível em: https://cpers.com.br/wp-content/uploads/2019/09/11.-Pedagogia-daIndigna\%C3\%A7\%C3\%A3o.pdf. Acesso em: 07 maio 2021.

FROZ, Sarah Silva; SANTOS, Silvana Maria P. 2015, História e ficção: a discursividade feminina em narrativas de Carolina Maria de Jesus. In: WALTY, Ivete Lara Camargos; MOREIRA, Terezinha Taborda Violência e escrita literária. Belo Horizonte: PUC Minas, 2020. E-book. p. 147-169. Disponível em: https://issuu.com/cespuc-centrodeestudosluso-afrobra/docs/violencia_20e_20escrita_20literaria. Acesso em: 23 fev. 2021.

GARCIA, Sandra Maria. Conhecer os homens a partir do gênero e para além do gênero. In: ARILHA, Margareth; UNBEHAUM, Sandra; MEDRADO, Benedito (org.). Homens e masculinidades: outras palavras. São Paulo: 34, 1998. E-book. p. 31-50. Disponível em: <https://www.google.com.br/books/edition/Homens_e_masculinidades/76nON3lhdzIC?hl=pt -BR\&gbpv=0>. Acesso em 25 nov. 2020.

GOMES 2015, Ecos sociais do homicídio de mulheres na narrativa contemporânea. In: KAMITA, Rosana C., FONTES, Luísa C. S. (org.). Mulher e Literatura: vozes consequentes. Iha de Santa Catarina: Mulheres, 2015. E-book. p. 197-214. Disponível em: https://issuu.com/gtamulhernaliteratura/docs/livro_eletr_nico_do_gt_a_mulher_na. Acesso em 20 fev. 2021.

HOLLANDA, Heloísa Buarque de. Explosão feminista: arte, cultura, política e universidade. São Paulo: Companhia das Letras, 2018. Disponível em:

<https://www.companhiadasletras.com.br/trechos/14358.pdf>. Acesso em: 07 maio 2021.

IPEA. Atlas da violência. Brasília; Rio de Janeiro, 2020. Disponível em: https://www.ipea.gov.br/atlasviolencia/filtros-series/3/violencia-por-raca-e-genero. Acesso em: 10 maio 2021.

IPEA. Atlas da violência. Brasília; Rio de Janeiro, 2020. Disponível em: https://www.ipea.gov.br/atlasviolencia/download/24/atlas-da-violencia-2020. Acesso em: 14 maio 2021.

JAFFE, Noemi. Prefácio. In: MAGLIO, Maria Fernanda Elias. Enfim, Imperatriz. São Paulo: Patuá, 2017.

MAGLIO, Maria Fernanda Elias. Enfim, Imperatriz. São Paulo: Patuá, 2017.

MAGLIO, Maria Fernanda Elias. 179. Resistência. São Paulo: Patuá, 2019.

MAGLIO, Maria Fernanda Elias. Você me espera para morrer? São Paulo: Patuá, 2020. 
MELO, Flavia. Não é fumaça, é fogo! Cruzada antigênero e resistências feministas no Brasil.

Revista Estudos Feministas, Florianópolis, v. 28, n. 3, 2020. Disponível em:

https://periodicos.ufsc.br/index.php/ref/article/view/72564. Acesso em: 10 maio 2021.

MIGNOLO, W. What Does It Mean to Decolonize? In: Mignolo, Walter; WALSH,

Catherine. (ed.). On Decoloniality: concepts, analytics, praxis. Durham and London: Duke University Press, 2018. Disponível em: https://rampages.us/goldstein/wpcontent/uploads/sites/7807/2018/08/Mignolo-and-Walsh-2018-On-Decoloniality-ConceptsAnalytics-Praxis.pdf. Acesso em: 07 maio 2021.

MIGNOLO, Walter. Desafios decoloniais hoje. Epistemologias do Sul, Foz do Iguaçu, v. 1, n. 1, p.12-32, 2017.

MORIN, E. Os sete saberes necessários à educação do futuro. 2. ed. São Paulo: UNESCO Brasil, 2000.

POE, E. A. A filosofia da Composição. In: POE, Edgar Allan. A filosofia da composição.

Poemas e ensaios. Tradução de Oscar Mendes e Milton Amado. Rio de Janeiro: Globo, 1985.

PORTO. Saindo do armário e registrando amores e dores: homoafetividade em contos brasileiros do século XXI. In: GOMES, Gínia Maria (org.). (Des)contextos da narrativa brasileira contemporânea. Frederico Westphalen/RS: URI, 2017. p. 203-218.

QUEIRÓZ, Josiane M.; TEIXEIRA, Maria S. Corpo em debate: a objetificação e sexualização da mulher negra. In: V Seminário Internacional Enlaçando Sexualidades, 5, Salvador, 2017. Anais [...]. Salvador: Realize, 2017. Disponível em: https://www.editorarealize.com.br/editora/anais/enlacando/2017/TRABALHO_EV072_MD1 _SA24_ID402_17072017210303.pdf. Acesso em: 20 mar. 2021.

RIBEIRO, Djamila. Lugar de fala. São Paulo: Sueli Carneiro; Jandaíra, 2020. (Coleção Feminismos Plurais).

ROSSINI, T. N. A. Construção do feminino na literatura: representando a diferença. Trem de Letras, v. 3, n. 1, p. 97-111, 2016. Disponível em: https://publicacoes.unifalmg.edu.br/revistas/index.php/tremdeletras/article/view/459. Acesso em: 20 mar. 2021

SILVA, Renata Rafaela Borges. O pensamento decolonial no romance de Ana Paula Maia, 2020. Trabalho de Conclusão de Curso (Especialização em Estudos Literários e Ensino de Literatura) - Faculdade de Letras, Universidade Federal de Goiás, Goiás, 2020a.

Disponível em:

<https://files.cercomp.ufg.br/weby/up/1148/o/Renata_Rafaela_Borges_da_Silva.pdf>. Acesso em: 29 fev. 2021.

SILVA, Assunção de Maria Sousa e. Universo feminino insubmisso. In: WALTY, Ivete Lara Camargos; MOREIRA, Terezinha Taborda (org.). Violência e escrita literária. Belo Horizonte: PUC Minas, 2020b. E-book. p. 128-146. Disponível em: https://issuu.com/cespuccentrodeestudosluso-afro-bra/docs/violencia_20e_20escrita_20literaria. Acesso em: $23 \mathrm{fev}$. 2021.

SZYMANSKI, D. M.; MOFFIT, L. B.; CARR, E. R.. Sexual Objectification of Women: Advances to Theory and Research. The Counseling Psychologist, v. 39, n. 1, p; 6-38, 2011. 
Disponível em: https://www.apa.org/education/ce/sexual-objectification.pdf. Acesso em 06 mar. 2021.

TIBURI, Marcia. Feminismo em comum: para todas, todes e todos. 8.ed. Rio de Janeiro: Rosa dos Tempos, 2018. 126 p.

VENUTI, Lawrence. Translation, Heterogeneity, Linguistics. Érudit. v.9, n.1 p.90-115, 1996. Disponível em: https://core.ac.uk/download/pdf/59325768.pdf. Acesso em: 10 mar. 2021.

WALSH, Catherine. Interculturalidad crítica y pedagogía de-colonial: in-surgir, re-existir y re-vivir. In: MEDINA, Patrícia (org.). Educación Intercultural en América Latina: memorias, horizontes históricos y disyuntivas políticas. México: Universidad Pedagógica Nacional; CONACYT; Plaza y Valdés, 2009. p. 25-42.

Recebido em março de 2021.

Aprovado em maio de 2021. 